\title{
Clinical diagnosis of pelvic endometriosis: a scoping review
}

\author{
Hedyeh Riazi ${ }^{1}$, Najmeh Tehranian ${ }^{1 *}$, Saeideh Ziaei $^{{ }^{*}}$, Easa Mohammadi², Ebrahim Hajizadeh ${ }^{3}$ and Ali Montazeri ${ }^{4,5}$
}

\begin{abstract}
Background: Accurate and timely diagnosis of endometriosis is associated with confusion. Clinical manifestations, imaging techniques, biomarkers and surgical techniques are used as diagnostic approaches. This paper reviews current evidence on clinical manifestation in order to help practitioners and perhaps improve women's health.

Methods: A review of the literature on clinical diagnosis of pelvic endometriosis that appeared in the English language biomedical journals was performed using PubMed, Science Direct and Google Scholar. The search strategy included the combination of key words 'endometriosis' and 'diagnosis' or 'clinical diagnosis' in the titles or abstracts of articles. The search included all papers published during the year 2000 to 2014. Then, the findings were classified in order to summarize the evidence.

Results: Using the Preferred Reporting Items for Systematic Reviews and Meta-Analyses (PRISMA) statement, in all 51 papers were found relevant and included in this review. In general we found three categories of diagnostic approaches for clinical manifestation including: i) diagnosis via symptoms obtained from history taking, ii) diagnosis via signs obtained from physical examination and iii) diagnosis via risk factors obtained from history taking.

Conclusion: Diagnosis of endometriosis is a matter of concern. Since the disease is associated with diverse clinical symptoms and signs, deeper and more comprehensive consideration according to patient's history and clinical findings is recommended for early and more accurate detection in order to prioritize women for further investigation and contribute to its early management.
\end{abstract}

\section{Background}

Endometriosis is a disease with considerable prevalence. It has been estimated to affect $10 \%$ to $15 \%$ of women of reproductive age [1]. The disease has several impacts in general physical, mental, and social well-being. The annual cost for hospital admission is estimated to be in a total around 54 million euros [2]. Diagnostic delay of endometriosis is a problematic issue [3] and it takes 8 to 11 years to be diagnosed with long and expensive diagnostic methods $[2,4]$. Thus it is essential to contemplate diagnosis as an important topic. The best method for early diagnosis of endometriosis is still full of unknown issues. Research on the diagnosis of endometriosis currently interfaces with four areas including clinical manifestations, imaging techniques, biomarkers and

\footnotetext{
* Correspondence: Tehranian@modares.ac.ir; ziaei_sa@modares.ac.ir 'Department of Reproductive Health and Midwifery, Faculty of Medical Sciences, Tarbiat Modares University, Jalal-e Al Ahmad Highway, P.O Box 14115-331, Tehran, Iran

Full list of author information is available at the end of the article
}

surgical techniques [5]. Laparoscopy, which is considered as the golden standard in endometriosis diagnosis has considerable risks [5], and other diagnostic methods are presented as inaccurate and with some limitations [6]. Therefore it seems that for developing clinical and non-surgical approaches for early detection of disease, effort is needed to have a better understanding of signs and symptoms of the disease [7].

Although there are several useful overview papers on endometriosis, most published papers are unfocused and usually discuss about all aspects of the disease including pathophysiology, diagnosis and treatment. While there is not any internationally recognized noninvasive method for diagnosis, most presurgical diagnostic methods are clinical judgment based on medical history, symptoms and signs [8]. Thus, this study aimed to review the literature on clinical diagnosis of endometriosis in order to discover the clinical criteria for achieving broader and 
deeper insight on the topic. Clinical manifestations of endometriosis are very broad and diverse issue with a wide range of changes [9]. Particulalrly here we focus on current research on the history taking and physical examination of endometriosis. It is hoped that this review may help to bring more attention about clinical diagnosis of endometriosis and consequently aid in decreasing diagnostic delay and perhaps contribute to improved women' health.

\section{Methods}

\section{Definition}

Endometriosis is defined as the presence of endometrial tissue (gland and struma) outside the uterus [10]. Endometriosis has been found in almost all of the tissues and organs of the body [11]. In this study we focused on pelvic endometriosis because pelvic endometriosis is the most common form of the disease, and it mostly affects women during their reproductive life [12].

\section{Search engines}

The search engines included PubMed, Science Direct and Google Scholar using the Preferred Reporting Items for Systematic Reviews and Meta-Analyses (PRISMA) guideline [13].

\section{Search strategy}

The search strategy included the combination of key words 'endometriosis' and 'diagnosis' or 'clinical diagnosis' in the titles or abstracts of articles.

\section{Inclusion and exclusion criteria}

All qualitative and quantitative articles in English language biomedical journals from year 2000 to 2014 on pelvic endometriosis were included. Case reports and articles on non-pelvic endometriosis were excluded. The year 2000 was chosen because the intention was to include more recent literature in this systematic review. The initial search was carried out in January 2013 and updated twice in March 2014 and February 2015.

\section{Data synthesis}

The findings from each idivdual paper on clinical diagnosis were retrieved, and were classified. Then different tables were provided to summriaze and present the findings.

\section{Results}

\section{Descriptive findings}

A total of 2749 citations were identified and after exclusion of duplicates, the abstracts of 1272 citations were screened. Of these, 113 papers were found relevant. However, 51 articles met inclusion criteria and were included in this review. The study selection process is shown in Figure 1. Overall we found 16 overview/commentary publications [2,9,14-27], 33 original research articles $[1,7,8,11,12,28-53]$, two meta-analysis [54,55] and 2 systematic reviews $[56,57]$.

\section{Review of overview papers}

A summary of overview/commentary publications is presented in Table 1. In general, these articles focused mainly on symptoms and treatment of the endometriosis. The emphasis of most papers was on pain, infertility and chronic fatigue.

\section{Clinical diagnosis}

Clinical diagnosis was achieved by different approaches. We have classified these methods in three groups: i) clinical diagnosis by symptoms obtained from history taking, ii) clinical diagnosis by signs obtained from physical examination and iii) clinical diagnosis by risk factors obtained from history taking. These are summarized as follows:

\section{Clinical diagnosis by symptoms obtained from history taking}

By taking a careful history of patients and considering their symptoms, the disease may be greatly suspected. Many studies recognized symptoms, which were very common such as cyclic or perimenstrual symptoms [16]. A summary of findings on symptoms obtained from history taking are presented here:

Pain Included dysmenorrhea (during and at the end of menstruation) [2,7-9,15-17,19-26,28,29,32-37,42,53,54], pelvic pain before and during menstruation $[2,7,14$, $16-18,21,23,25,33,34]$, and pain during sexual intercourse or after sex (dyspareunia) [2,7-9,11,15-17,19-25]. Dyspareunia was occurred only with deep thrusting [23]. Lower abdominal pain or suprapubic pain, lower back pain $[11,14,17,20,21,29]$ and loin pain $[17,20]$ were also mentioned. Pelvic pain was present as chronic pelvic pain (lasting $\geq 6$ months) and patients reported that they were suffering from intermenstrual pain (non-period pelvic pain) or ovulation pain $[2,7,15,16,19-24,33,34,37,42]$. Rectal pain was also mentioned [11,21]. Pain character was found to be throbbing [31,35], dull or sharp and exacerbated by physical activity [20]. Pain often worsened over time and changed in character [20].

Menstrual symptoms Included hypermenorrhea, menorrhagia, premenstrual spotting for 2-4 days $[7,9,11$, $15,22,23,29,32]$, mid cycle bleeding, irregular bleeding, and irregular periods $[2,16,19,26,29]$. 


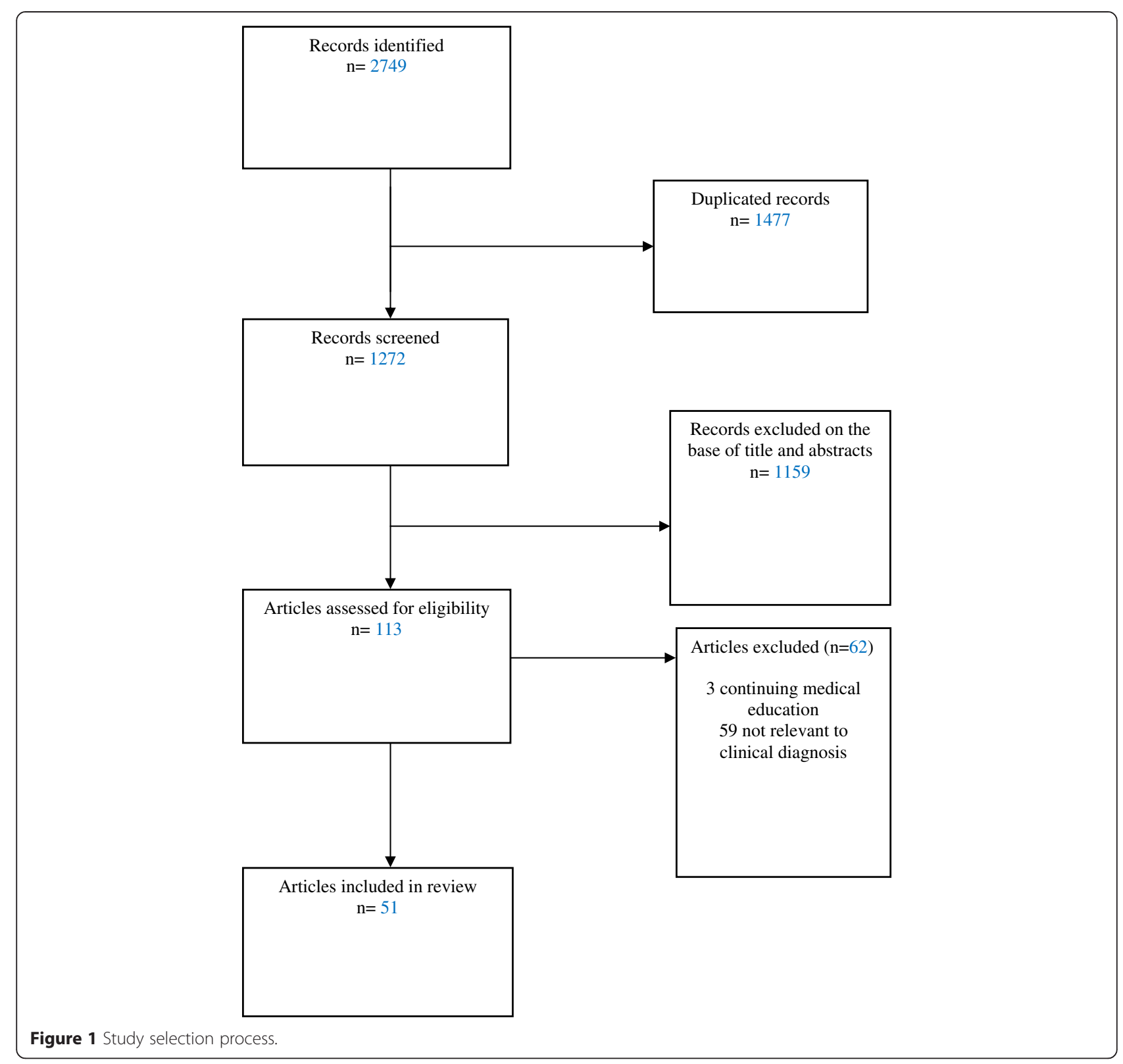

Urinary problems Included dysuria, hematuria, urinary frequency, urinary tract infection, and cystitis $[11,14,17$, $18,21,23,29,32,34,36,42]$.

Digestive symptoms Included abdominal bloating, diarrhea with period, painful bowel movements and painful defecation (dyschezia) during menses, hematochezia, nausea and stomach upset at the time of period, constipation, [11,14,16-20,22,24,25,28,29,34,35], irritable bowel syndrome (IBS) $[7,32]$ and early satiety $[20]$.

Gynecologic comorbidities Included gynecological infections and low resistance to infection, candidiasis $[11,29,33]$ infertility $[2,7-9,16,17,19,21,23-25,29,34,36,37$,
$42,45]$, pelvic inflammatory disease, ovarian cysts [7,32, 33] and postcoital bleeding [7].

Comorbidities Included a wide range of allergies and allergic disease, dizziness, migraines and headaches at the time of period or before $[11,23,29,33,34]$, and mitral valve prolapse [29].

Social life symptoms Some symptoms such as inability to carry on normal activities including work or school were reported by patients [29]. Depressed and anxious feelings [11], irritability or premenstrual tension syndrome [23], and psychoemotional distress and alexithymia were also mentioned [47]. 


\begin{tabular}{|c|c|c|c|}
\hline Author(s) [Ref.] & Year & Results for symptoms & Results for signs \\
\hline Valle [14] & 2002 & $\begin{array}{l}\text { Pelvic pain that often is worse just before and during menstruation, } \\
\text { hypermenorrhea, premenstrual staining, dyspareunia, suprapubic pain, dysuria, } \\
\text { hematuria, painful defecation (dyschezia), lower back pain. }\end{array}$ & $\begin{array}{l}\text { Local tenderness in cul de sac or uterosacral ligaments, adnexal enlargement or } \\
\text { tenderness, pelvic masses. }\end{array}$ \\
\hline Spaczynski and Duleba. [15] & 2003 & $\begin{array}{l}\text { Chronic pelvic pain consists of dysmenorrhea, intermenstrual pain, and } \\
\text { dyspareunia. }\end{array}$ & $\begin{array}{l}\text { Bluish implants typical of endometriosis or red, hypertrophic lesions bleeding on } \\
\text { contact, usually in the posterior fornix. lateral cervical displacement, cervical } \\
\text { stenosis. Retroversion, decreased or absent mobility of uterus and tenderness. } \\
\text { Tender masses, nodules, and fibrosis appreciated on palpation of the upper vagina, } \\
\text { cul-de-sac, uterosacral ligaments, or rectovaginal septum. }\end{array}$ \\
\hline Kennedy et al. [16] & 2005 & $\begin{array}{l}\text { Severe dysmenorrhea, deep dyspareunia, chronic pelvic pain, ovulation pain, } \\
\text { cyclical or perimenstrual symptoms (e.g. bowel or bladder associated) with or } \\
\text { without abnormal bleeding, infertility and chronic fatigue. }\end{array}$ & $\begin{array}{l}\text { Pelvic tenderness, a fixed retroverted uterus, tender uterosacral ligaments or } \\
\text { enlarged ovaries on examination. The diagnosis is more certain if deeply } \\
\text { infiltrating nodules are found on the uterosacral ligaments or in the pouch of } \\
\text { Douglas, and/or visible lesions are seen in the vagina or on the cervix. The } \\
\text { findings may, however, be normal. }\end{array}$ \\
\hline Mounsey et al. [17] & 2006 & $\begin{array}{l}\text { Pelvic pain, back pain, dyspareunia, dysmenorrhea loin pain, dyschezia, pain with } \\
\text { micturition and infertility. }\end{array}$ & $\begin{array}{l}\text { Tender nodules in the posterior vaginal fornix, uterine motion tenderness, a } \\
\text { fixed and retroverted uterus, or tender adnexal masses. }\end{array}$ \\
\hline Denny and Mann. [18] & 2007 & $\begin{array}{l}\text { Pain around menstruation, dyspareunia, dyschezia, cyclical dysuria and extreme } \\
\text { fatigue. }\end{array}$ & Not discussed. \\
\hline Amer [19] & 2008 & $\begin{array}{l}\text { Dysmenorrhoea, dyschezia, hematochezia, dysurea, haematurea, dyspareunia, } \\
\text { chronic pelvic pain, heavy and/or irregular periods, premenstrual spotting, } \\
\text { infertility. }\end{array}$ & $\begin{array}{l}\text { Tenderness on cervical movement, thickening and tenderness of the uterosacral } \\
\text { ligaments, fullness or mass in the pouch of Douglas (POD), fixation and } \\
\text { retroversion of the uterus, rectovaginal nodule. Adnexal (or even a pelvi- } \\
\text { abdominal) mass in women with large endometriomas. }\end{array}$ \\
\hline Luisi et al. [2] & 2009 & $\begin{array}{l}\text { Severe dysmenorrhea, deep dyspareunia, chronic pelvic pain, ovulation pain, } \\
\text { cyclical or perimenstrual symptoms with or without abnormal bleeding, } \\
\text { infertility and chronic fatigue. }\end{array}$ & Not discussed. \\
\hline Giudice. [20] & 2010 & $\begin{array}{l}\text { Chronic pelvic pain (lasting } \geq 6 \text { months), dysmenorrhea, dyspareunia, deep } \\
\text { pelvic pain, and lower abdominal pain with or without back and loin pain. The } \\
\text { pain can be continuous, and it can be dull, throbbing, or sharp, and } \\
\text { exacerbated by physical activity. Bladder- and bowel associated symptoms } \\
\text { (nausea, distention, and early satiety) are typically cyclic. Burning or hypersensi- } \\
\text { tivity symptoms that are suggestive of a neuropathic component (infrequently). }\end{array}$ & A pelvic mass, immobile pelvic organs, and rectovaginal nodules. \\
\hline Altman and Wolcyzk. [21] & 2010 & $\begin{array}{l}\text { Chronic pelvic pain, dysmenorrhea, dyspareunia, infertility, back pain, dyschezia, } \\
\text { rectal pain, diarrhea, constipation, dysuria, hematuria, infertility, chronic fatigue } \\
\text { and psychosocial stressors. }\end{array}$ & $\begin{array}{l}\text { Palpable tender nodules in the cul-de-sac or uterosacral ligaments; localized } \\
\text { tenderness in the cul-desac, uterosacral ligaments, or rectovaginal septum; pain } \\
\text { with uterine movement; enlarged or tender adnexal masses; and fixation of adnexa } \\
\text { or uterus in a retroverted position. Red, blue, or hemorrhagic nodules may also be } \\
\text { visualized on the external genitalia, vagina, or cervix. }\end{array}$ \\
\hline Okeke and Ikeako. [9] & 2011 & Dysmenorrhea, dyspareunia, menorrhagia and infertility. & Not discussed. \\
\hline Koninckx et al. [22] & 2012 & $\begin{array}{l}\text { Hypogastric pain, especially dysmenorrhea, deep dyspareunia, severe chronic } \\
\text { pain, mictalgia, and dyschezia. }\end{array}$ & Not discussed. \\
\hline Acién and Velasco [23] & 2013 & $\begin{array}{l}\text { Dysmenorrhea (during and at the end of menstruation), deep dyspareunia, } \\
\text { chronic pelvic pain, and infertility premenstrual spotting for 2-4 days, headache, } \\
\text { irritability, or premenstrual tension syndrome. }\end{array}$ & Not discussed. \\
\hline Carneiro M M et al. [24] & 2013 & $\begin{array}{l}\text { Dysmenorrhea, dyspareunia, dyschezia, gastrointestinal symptoms, chronic pelvic } \\
\text { pain, infertility. }\end{array}$ & $\begin{array}{l}\text { Pelvic tenderness, a fixed retroverted uterus, tender uterosacral ligaments or } \\
\text { enlarged ovaries, uterosacral nodularity. }\end{array}$ \\
\hline Schrager et al. [25] & 2013 & Debilitating pelvic pain, dysmenorrhea, dyspareunia, and decreased fertility. & Not discussed. \\
\hline
\end{tabular}


Table 1 A summary of overview/commentary papers on clinical symptoms and signs (Continued)

Mehedintu et al. [26] 2014 Severe dysmenorrhea, non-cyclical chronic pelvic pain, dysfunctional uterine bleeding, infertility, dyspareunia, painful defecation during menstruation, urinary tract symptoms and gastrointestinal symptoms

Bhattacharjee et al. [27] 2014 Dysmenorrhea, deep dyspareunia, infertility, abnormal uterine bleeding, non-cyclic pain, menstrual cycle abnormalities, constipation, chronic fatigue, heavy or long uncontrollable me problems including diarrhea, bloating and painful defecation, extreme pain in legs and thighs, back pain, mild to extreme pain during intercourse, pain from adhesions which may bind an ovary to the side of the pelvic wall, or they may extend between the bladder and the bowel, uterus, extreme pain with or witho the presence of menses, premenstrual spotting, mild to severe fever, headaches,

Non-specific pelvic tenderness, localized tenderness in the pouch of Douglas, thickened nodular uterosacral ligaments, fixed retroverted uterus, palpable fixed cystic adnexal mass displacements of cervix \& presence of nodules in the rectovaginal pouch or uterosacral ligaments, nodularity or tenderness in the uterosacral ligament, bluish or red powder burn lesions may be seen in the cervix or posterior fornix of the vagina (which may be tender or bleed on touch), bluish nodules in the posterior fornix, a fixed retroverted tender uterus or a firm fixed pouch of Douglas 
Musculoskeletal symptoms Included muscle/bone pain, joint pain and leg pain [11].

Other symptoms Patients reported suffering from chronic fatigue, exhaustion, low energy and low-grade fever $[2,11,16,18,21,29]$. Women also reported burning or hypersensitivity, symptoms that were suggestive of a neuropathic component [20]. Mictalgia was also mentioned [22]. Previous surgery for endometriosis also was found a considerable factor [31,42]. The findings are presented in Table 2.

\section{Clinical diagnosis by signs obtained from physical examination}

Clinical signs of the disease that identified by physical examination (pelvic examination by inspection and palpation) included a broad range of signs. External genitalia and the vaginal surface were usually unremarkable [15]. Findings of physical examination are listed as follows:

External genitalia Visible red, blue, or hemorrhagic nodules on the external genitalia [21].

Vagina Visible red, blue, or hemorrhagic nodules on the vagina, and tender masses, nodules, and fibrosis on palpation of the upper vagina $[8,15-17,21]$.

Cervix Visible lesions on the cervix, tenderness on cervical movement, lateral cervical displacement, and cervical stenosis $[15,16,19,21,37]$.

Uterus A fixed (decreased or absent mobility) and retroverted uterus, and uterine motion tenderness in pelvic examination $[8,15-17,19,21,24]$.

Adnexa Tender or fixed adnexal masses resulting from endometriomas, adnexal enlargement, and pelvic masses $[8,14,17,19,21]$.

Posterior vaginal fornix Tender nodules in the posterior vaginal fornix, bluish implants typical of endometriosis or red, hypertrophic lesions bleeding on contact $[15,17]$.

Pouch of Douglas Fullness or mass or nodularity or pain in the pouch of Douglas, local tenderness or palpable tender nodules in cul de sac $[8,14,16,19,30]$.

Rectovaginal septum Tender masses, nodules, and fibrosis of the rectovaginal septum [15,19-21,37].

Uterosacral ligament Thickening, pain or tenderness or nodularity in uterosacral ligament $[8,14-16,19,21,24,30]$.
The most reported signs included changes in uterus, cervix, adnexa and uterosacral ligament palpation. The findings are shown in Table 2.

\section{Clinical diagnosis by risk factors obtained from history taking}

Although it was reported that the following risk factors alone are not enough, they could potentially direct physicians toward clinical diagnosis of pelvic endometriosis. All risk factors are presented in Table 3.

Risk factors related to menstrual periods Included early menarche (before age 11-13) or late menarche (menarche at $\geq 14$ y) $[12,15,20,33,39,54]$, short menstrual cycle ( $\leq 27$ days) $[15,17,20,32,58]$, longer menstrual flow ( $\geq 7$ days) $[15,30]$, and spotting before onset of menses $[11,15,19,23,29,51]$. Late menopause [20], early history of dysmenorrhea [12], obstruction of menstrual outflow for example mullerian anomalies and use of pads and tampons were other risk factors $[17,20]$.

Risk factors related to patients' characteristics Patients who were taller, thinner and had lower body mass index, red hair $[1,15,39,40,43]$ and dysplastic nevi [15] were found to be more prone to pelvic endometriosis. Higher education was considered as another risk factor [18]. Rh-negativity [46], severe teenage acne [48] and blue eye color [49] were also mentioned as risk factors for pelvic endometriosis.

Risk factors related to obstetrics and gynecologic history These included not having a history of pregnancy or delivery, [15,39-42], late initiation of sexual activity $(\geq 21 \mathrm{y})$ and never used OCPs $[17,39]$.

Risk factors related to family history Included family history of endometriosis for example mother or sister $[15,17,36,38,44]$. The relative risk of endometriosis in female siblings was found to be 5.7 [42].

Risk factors related to nutrition Consumption of red meat and trans fats were associated with an increased risk of endometriosis, and eating fruits, green vegetables, and omega-3 long-chain fatty acids were associated with a decreased risk [20].

Risk factors related to embryonic factors Included exposure to diethylstilbestrol in utero and low birth weight [20].

Risk factors related to patient's habits Consumption of one or more alcoholic drinks per week $[17,39,40,55]$. 
Table 2 Main diagnostic symptoms and signs obtained from history taking and physical examination respectively

\begin{tabular}{|c|c|c|c|}
\hline Author(s) [Ref.] & Year & Study design & $\begin{array}{l}\text { Sam } \\
\text { size }\end{array}$ \\
\hline Eskenazi et al. [8] & 2001 & $\begin{array}{l}\text { Prospective study (study sample); } \\
\text { retrospective record review (test } \\
\text { sample). }\end{array}$ & 90 \\
\hline
\end{tabular}

\section{Sample Findings}

size

Symptoms: Dysmenorrhea, pelvic pain, dyspareunia and infertility.

Signs: Uterosacral ligament scarring, nodularity, or pain, nodularity or pain in the pouch of Douglas, vaginal endometriotic lesions, painful or fixed adnexal masses, and fixed uterus or pain on movement of uterus in pelvic examination.

\begin{tabular}{lll}
\hline Chapron et al. [28] & 2002 & Retrospective analysis \\
\hline Ballweg L M [29] & 2004 Cross sectional & 7000
\end{tabular}

Signs: Endometriotic lesions seen in speculum examination and classic, painful, spheric nodule or painful induration in palpation.

2004 Cross sectional 7000

\section{Symptoms: Fatigue, exhaustion, low energy, numerous} gastrointestinal symptoms, abdominal bloating, diarrhea, painful bowel movements or other intestinal upset, nausea and stomach upset at time of period, a wide range of allergies and allergic disease; heavy or irregular bleeding, pain with or after sex, dizziness and headaches at the time of the period and other debilitating symptoms (unable to carry on normal activities, including work or school), in addition to the classic symptom of pain (dysmenorrhea, pain with or after sex (dyspareunia). Lower back pain, pain in the rectum, irregular bleeding, low resistance to infection, infertility, premenstrual spotting, low-grade fever, Pain related to urination, candidiasis, mid cycle bleeding, mitral valve prolapse.

Lemaire. [11

2004 Descriptive, cross-sectional correlational study.

298

Symptoms: Menstrual cramping, fatigue, lower back pain, heavy menstrual flow, non-period pelvic pain, diarrhea with period, allergy, urinary frequency, pain with intercourse, depressed feelings, constipation, muscle/bone pain, headache, anxious feelings, joint pain, leg pain, spotting between/before periods, rectal pain, urinary infection, yeast infection.

\begin{tabular}{|c|c|c|c|c|}
\hline Cheewadhanaraks et al. [30] & 2004 & Prospective study & 116 & $\begin{array}{l}\text { Signs: Tenderness and/or nodularity of the cul-de-sac and/or } \\
\text { uterosacral ligament(s). }\end{array}$ \\
\hline Chapron et al. [31] & 2005 & Cross sectional & 134 & $\begin{array}{l}\text { Symptoms: Painful defecation during menses, severe dyspareunia, } \\
\text { pain other than noncyclic, and previous surgery for endometriosis. }\end{array}$ \\
\hline Ballard and Mangubat. [32] & 2007 & $\begin{array}{l}\text { National community-based } \\
\text { case-control }\end{array}$ & 27715 & $\begin{array}{l}\text { Symptoms: Pelvic pain and dysmenorrhea, dyspareunia, } \\
\text { menorrhagia, urinary symptoms (dysuria, cystitis, and urinary tract } \\
\text { infections), irritable bowel syndrome (IBS), pelvic inflammatory } \\
\text { disease and ovarian cysts. }\end{array}$ \\
\hline Flores et al. [33] & 2008 & Cross sectional & 1285 & $\begin{array}{l}\text { Symptoms: Dysmenorrhea, dyspareunia, conceiving problems, } \\
\text { chronic pelvic pain, ovarian cysts, migraines, and gynecological } \\
\text { infections. }\end{array}$ \\
\hline Greene et al. [34] & 2009 & Cross-sectional & 4334 & $\begin{array}{l}\text { Symptoms: Pelvic pain, menstrual pain, ovulatory and } \\
\text { nonmenstrual pain, lifetime presence of all three pain types, heavy } \\
\text { bleeding, infertility, bowel symptoms, urinary symptoms, pain with } \\
\text { urination, nausea/stomach upset or dizziness/headache during } \\
\text { menses. }\end{array}$ \\
\hline Ballard et al. [35] & 2010 & Prospective questionnaire-based & 185 & Symptoms: Throbbing pain and dyschezia. \\
\hline Abbas et al. [7] & 2012 & Cohort & 62,323 & $\begin{array}{l}\text { Symptoms: Dysmenorrhea, dyspareunia, intermenstrual pain, } \\
\text { menorrhagia, ovarian cysts, pelvic pain, postcoital bleeding, } \\
\text { infertility, irritable bowel syndrome, pelvic inflammatory disease. }\end{array}$ \\
\hline Nnoaham et al. [36] & 2012 & $\begin{array}{l}\text { Prospective, observational, two- } \\
\text { phase study }\end{array}$ & 1,396 & $\begin{array}{l}\text { Symptoms: Dysmenorrhea, dyspareunia, pelvic pain, Bowel/urinary } \\
\text { symptoms, infertility, family history. }\end{array}$ \\
\hline Hadisaputra. [37] & 2013 & Cross sectional & 80 & $\begin{array}{l}\text { Symptoms: Infertility, dysmenorrhea, dyspareunia and chronic } \\
\text { pelvic pain. Signs: Rectovaginal nodule and cervical tenderness. }\end{array}$ \\
\hline Cavaggioni et al. [47] & 2014 & Case- control & 80 & $\begin{array}{l}\text { Symptoms: Mood and anxiety disorders, obsessive-compulsive } \\
\text { malfunction, depression, alexithymia. }\end{array}$ \\
\hline Heitmann et al. [51] & 2014 & Retrospective cohort study & 80 & Symptom: Premenstrual spotting of $\geq \_2$ days \\
\hline Walch et al. [52] & 2014 & $\begin{array}{l}\text { Prospective, controlled clinical } \\
\text { trial }\end{array}$ & 102 & Symptom: Cyclic leg pain \\
\hline Barbosa et al. [53] & 2014 & Cross sectional & 387 & Symptom: Dysmenorrhea was the only clinical symptom \\
\hline
\end{tabular}


Table 3 Risk factors or characteristics of endometriosis patients

\begin{tabular}{|c|c|c|c|c|}
\hline Author(s) [Ref.] & Year & Study design & Sample size & Findings \\
\hline Kashima et al. [38] & 2004 & Case-control & 623 & Familial tendency. \\
\hline Hediger et al. [39] & 2005 & Cohort study & 48 & $\begin{array}{l}\text { Taller, thinner and lower body mass index, late maturers } \\
\text { (menarche at } \geq 14 \text { y) and late to initiate sexual activity }(\geq 21 \\
\text { y), less likely to be gravid, parous, and a current smoker. }\end{array}$ \\
\hline Flores et al. [33] & 2008 & Cross-sectional & 1285 & $\begin{array}{l}\text { Longer length of menses, earlier menarche and shorter } \\
\text { cycle length. }\end{array}$ \\
\hline Parazzini et al. [40] & 2008 & Case-control & 672 & $\begin{array}{l}\text { More education, lower body mass index, never smoking } \\
\text { and null parity. }\end{array}$ \\
\hline Sinaii et al. [41] & 2008 & Cross-sectional & 940 & Pelvic pain, subfertility. \\
\hline Yi et al. [1] & 2009 & $\begin{array}{l}\text { Retrospective review of } \\
\text { clinical records }\end{array}$ & 481 & Lower BMI. \\
\hline Bazot et al. [42] & 2009 & $\begin{array}{l}\text { Retrospective } \\
\text { longitudinal study }\end{array}$ & 92 & $\begin{array}{l}\text { Infertility, previous surgery for endometriosis, nulliparity, } \\
\text { noncyclic chronic pelvic pain, dysmenorrhea, deep } \\
\text { dyspareunia, painful defecation, dysuria and asthenia. }\end{array}$ \\
\hline Treloar et al. [12] & 2010 & Case-control & 268 & Early menarche and early history of dysmenorrhea. \\
\hline Lafay et al. [43] & 2011 & Case-control & 476 & Lower body mass index. \\
\hline Chapron et al. [44] & 2011 & Cross-sectional & 229 & $\begin{array}{l}\text { Positive family history, more absenteeism from school } \\
\text { during menstruation, OC pill use for treating severe } \\
\text { primary dysmenorrhea. }\end{array}$ \\
\hline Nnoaham et al. [54] & 2012 & $\begin{array}{l}\text { Systematic review and } \\
\text { meta-analysis of case- } \\
\text { control studies. }\end{array}$ & 18 articles & Early menarche \\
\hline Peterson et al. [45] & 2013 & Cohort & 626 & Infertility history, dysmenorrhea and pelvic pain. \\
\hline Parazzini et al. [55] & 2013 & Metaanalysis & 15 articles & Alcohol consumption \\
\hline Borghese et al. [46] & 2014 & cross-sectional & 663 & Rhesus negativity \\
\hline Xie et al. [48] & 2014 & $\begin{array}{l}\text { prospective cohort } \\
\text { study }\end{array}$ & 88623 & Severe teenage acne. \\
\hline Vercellini et al. [49] & 2014 & Case-control & 771 & Blue eye color \\
\hline Tu et al. [50] & 2014 & $\begin{array}{l}\text { Prospective cohort } \\
\text { study }\end{array}$ & 9,585 & Prior OCP use in nulliparous women \\
\hline Bungum et al. [56] & 2014 & Systematic review & 5 articles & $\begin{array}{l}\text { Increased risk of allergic disorders (asthma, hay fever/ } \\
\text { allergic rhinitis of the sinus, eczema, food allergy, allergy to } \\
\text { either pollen, dust, trees, paint, grasses, cigarette smoke, } \\
\text { perfumes/fragrances, cleaning products, foods or } \\
\text { environmental chemicals) }\end{array}$ \\
\hline Bonocher et al. [57] & 2014 & Systematic review & 6 articles & $\begin{array}{l}\text { Inconclusiveness regarding the benefits of physical } \\
\text { exercise as a risk factor }\end{array}$ \\
\hline
\end{tabular}

Risk factors related to race Asian origin increased the risk of the disease [15].

However, prolonged lactation, multiple pregnancies, the combined oral contraceptive, smoking and exercise are reported as protective factors [20]. The most risk factors were related to menstrual periods, patients' characteristics and family history.

\section{Discussion}

The emphasis of this review was on several aspects of the clinical diagnosis of pelvic endometriosis. All factors that could have been of any help in clinical diagnosis of the disease were reviewed and classified. These findings divided in three main categories. Moreover this article showed that there were many more symptoms than have traditionally associated with endometriosis.
Usefulness of clinical signs and symptoms in the diagnosis of pelvic endometriosis in women who present with infertility was shown in some studies [17]. In addition, it has been reported that some symptoms had greater predictive value. The most commonly reported symptoms leading to a diagnosis were dysmenorrhea and pelvic pain. Treloar et al. reported that dysmenorrhea was associated with a 2.5 -fold increased risk of subsequent endometriosis [12]. Pelvic pain was reported by all patients in a study by Greene et al. [34]. Among the other symptoms leading to a diagnosis, subfertility and an ovarian mass were more commonly reported in stages 3-4, whereas dyspareunia was more common in stages 1-2 [41]. Women with endometriosis were 9 times as likely to report dyspareunia as compared to a control group [32]. In Nnoaham et al. study painful 
defecation during menstruation and a history of benign ovarian cysts strongly predicted any stages of the disease. The stage III and IV disease was predicted with good accuracy based on symptom-based model. They used several variables in their model including indications for surgery, menstrual history, dysmenorrhea, dyspareunia, pelvic pain, bowel/urinary symptoms, pregnancy/infertility history, personal characteristics and family history [36].

Chapron et al. showed that variables such as painful defecation during menses, severe dyspareunia, pain other than noncyclic, and previous surgery were considered as independent predictors for posterior deep infiltrating endometriosis. They showed a diagnostic model that used two independent predictors: painful defecation during menses and severe dyspareunia. The sensitivity of this model for diagnosing posterior deep infiltrating endometriosis was $74.5 \%$ and its specificity was $68.7 \%$. They concluded that standardized evaluation of painful symptoms is useful for screening the disease [31]. Pelvic inflammatory disease and ovarian cysts were 6 and 12 times as likely to be made in women with endometriosis [14].

Although no test provides strong evidence for the presence of endometriosis, the symptom of uterosacral pain had the highest positive likelihood ratio for the diagnosis of endometriosis [20]. In addition to the classic symptom of pain, other symptoms such as fatigue, exhaustion, low energy, gastrointestinal problems, abdominal bloating, and a range of allergic diseases also showed a positive association with endometriosis. These are usually dismissed because they are not widely known. These symptoms are very important. A study by Lemaire showed that the three symptoms with highest total symptom distress were fatigue or weariness, menstrual cramping and nonperiodic pelvic pain [11].

Women with endometriosis were twice as likely to report urinary symptoms such as dysuria, cystitis, and urinary tract infections compared with control group [14]. Sinaii et al. did not report any significant relationship between endometriosis and regular, vigorous exercise, regular use of talc as body powder and cigarette smoking [43], but other studies have found a significant association between smoking and endometriosis [40]. In Hediger study, patients were more likely to be late maturers (menarche at $\geq 14$ y) [39] while in other studies early menarche was often cited as a risk factor for endometriosis [12]. In Parazzini study age at menarche and lifelong type of menstrual cycles were not related to the risk of deep or pelvic and ovarian endometriosis [40]. So it seems that further studies are needed to clarify this relationship.

The risk of the disease raised by advancing age within the reproductive years, peaking among women aged 40-44 years [58]. The findings of the Ballweg's study indicated that the disease was more severe with an early age of onset and thus it is necessary to pay more attention to girls suffering from menstrual pain [29]. Most studies have shown a significant relationship between endometriosis and length of menstrual cycle, menstrual volume, occurrence of irregular menstrual periods, recent pelvic pain or dyspareunia except one [39] which may be attributed to the small sample size of the study. In the Flores's study among Puerto Rican women the diagnosis of endometriosis was significantly associated with dysmenorrhea, dyspareunia, and chronic pelvic pain, but not with menstrual cycle characteristics [33]. This was probably due to their study on Hispanic population. In Treloar et al. study no association was found between endometriosis and duration of natural menstruation, heaviness of flow, type of sanitary protection used and history of sexual intercourse during menstruation which may be due to recall bias or small size of control group [12]. Ballard and Mangubat showed that menorrhagia in women with endometriosis was 5 times higher that controls [32].

Lafay et al. showed that patients with the lowest BMI $(\leq 18.5)$ were at a higher risk of deep infiltrating endometriosis. BMI was significantly lower in deep infiltrating endometriosis and ovarian endometrioma patients but not for the superficial endometriosis patients [43]. In Yi et al. study, women with advanced-stage endometriosis had lower BMI than those with minimal or mild disease, and BMI was significantly associated with disease severity [1]. These findings are in line with other studies $[39,40]$, but in Kennedy study the risk of the disease was increased for women with greater peripheral fat [58]. Borghese et al. showed that Rh-negative women were twice as likely to develop endometriosis. [46]. However, there is controversy about the relationship between blood group and endometriosis $[46,59,60]$ and further investigation is needed to determine the role of blood groups in the development of endometriosis. In a study by Xie et al. it was reported that women who had severe teenage acne had a $20 \%$ increased risk of endometriosis. Probable mechanisms for such observation might be due to genetic factors, sex hormones including estrogens and immune malfunction [48]. Blue eye color also was another factor. It is argued that perhaps genetic factors, and vitamin $\mathrm{D}$ deficiency due to photo-sensitivity might lead to a relationship between eye color and endometriosis [49]. Several studies have shown that the risk of allergic disease could be increased with endometriosis [56].

In Kashima et al. study the relative risk of endometriosis in female siblings of patients was 5.7 [38], which were consistent with other findings [17]. These findings 
propose a familial tendency and a genetic factor for endometriosis.

Endometriosis occurs more commonly in middle-aged, upper class, ambitious, white women. This may occur due to greater access to medical care and diagnostic tests such as laparoscopy in these women [58]. Several studies have shown different results about the relationship between physical activity and endometriosis so there is inconclusiveness regarding the benefits of physical exercise as a risk factor for the disease [57].

Two important signs must be considered: deep dyspareunia and nodules in the pouch of Douglas [23]. Findings of physical examination vary significantly with location of endometriotic lesions. They can be seen on speculum examination in only $14 \%$ of patients, and a classic, painful, spheric nodule can be palpated in only $43 \%$ [28]. In Chapron study a nodule was found in $80 \%$ of patients with vaginal endometriosis, this rate dropped to only $35 \%$ and $33 \%$ in those with deep infiltrating endometriosis of the digestive tract and uterosacral ligaments, respectively [28]. High locations of deep infiltrating endometriosis lesions at the level of uterosacral ligaments, bottom of the pouch of Douglas and upper one-third of the posterior vaginal wall explain why results of routine clinical examination are so poor. Cheewadhanaraks showed a positive predictive value of tenderness and/or nodularity of the cul-de-sac and/or uterosacral ligament(s) in diagnosis of the endometriosis [30]. In Howard study no findings on physical examination, including cervical deviation, cervical tenderness, or paracervical tenderness were predictive for the disease [61] but in Bazot et al. study the sensitivity of physical examination was $73.5 \%$ for uterosacral ligament endometriosis, $50 \%$ for vaginal endometriosis and $46 \%$ for intestinal endometriosis. The accuracy of physical examination is higher during menstruation [42].

Eskenazi et al. reported that ovarian endometriosis, but not nonovarian endometriosis, could be reliably predicted with noninvasive procedures. They used history, pain reports, physical examination and ultrasound for prediction and found that these procedures have moderate success in predicting a surgical diagnosis of endometriosis [8].

Attempts to diagnose women using symptoms, clinical findings or ultrasonography had disappointing findings except, possibly, for ovarian endometriosis in Hediger et al. study [39]. Women with endometriosis experience significantly more gynecological, urological and bowel symptoms than women without endometriosis [32], and that the risk of endometriosis increases in women with endometriosis-related symptoms [7].

\section{Conclusion}

Clinical diagnosis of pelvic endometriosis is difficult. Thus considerable efforts are needed to improve the clinical diagnosis of pelvic endometriosis because it could help to prioritize women for further investigation and contribute to its early diagnosis. However, this review provides integrated findings from the literature containing issues related to signs, symptoms and risk factors. The findings suggest that better diagnosis of pelvic endometriosis need a careful and comprehensive investigation about risk factors during history taking and clinical visits. Perhaps every notes during this period by clinicians and midwifes might lead to timely diagnosis and treatment. Further studies with much more focus on signs and symptoms of the disease are recommended for clarifying the present contradictions.

\section{Competing interests}

The authors declare that they have no competing interests.

\section{Authors' contributions}

HR was the main investigator and carried out the study. NT and SZ supervised the study. EM and EH were the study advisors and involved in data synthesis. AM contributed to conducting the systematic review, the writing process, responded to the reviewers' comment and prepared the final draft. All authors read and approved the manuscript.

\section{Acknowledgments}

This manuscript was originated from the PhD thesis of the first author at Department of Midwifery and Reproductive Health, Faculty of Medicine, Tarbiat Modares University.

\section{Author details}

${ }^{1}$ Department of Reproductive Health and Midwifery, Faculty of Medical Sciences, Tarbiat Modares University, Jalal-e Al Ahmad Highway, P.O Box 14115-331, Tehran, Iran. Department of Nursing, Faculty of Medical Sciences, Tarbiat Modares University, Jalal-e Al Ahmad Highway, P.O Box 14115-331, Tehran, Iran. ${ }^{3}$ Department of Biostatistics, Faculty of Medical Sciences, Tarbiat Modares University, Jalal-e Al Ahmad Highway, P.O Box 14115-331, Tehran, Iran. ${ }^{4}$ Mental Health Research Group, Health Metrics Research Center, Iranian Institute for Health Sciences Research, ACECR, P.O Box 13185-1488, Tehran, Iran. ${ }^{5}$ Faculty of Humanity Sciences, University of Science \& Culture, ACECR, Tehran, Iran.

Received: 1 September 2014 Accepted: 24 April 2015 Published online: 08 May 2015

\section{References}

1. Yi KW, Shin JH, Park MS, Kim T, Kim SH, Hur JY. Association of body mass index with severity of endometriosis in Korean women. Int J Gynaecol Obstet. 2009;105:39-42

2. Luisi $S$, Lazzeri L, Ciani V, Petraglia F. Endometriosis in Italy: from cost estimates to new medical treatment. Gynecol Endocrinol. 2009;25:734-40.

3. Hudelist G, Fritzer N, Thomas A, Niehues C, Oppelt P, Haas D, et al. Diagnostic delay for endometriosis in Austria and Germany: causes and possible consequences. Hum Reprod. 2012;27:3412-6.

4. Rogers PA, D'Hooghe TM, Fazleabas A, Gargett CE, Giudice LC, Montgomery GW, et al. Priorities for endometriosis research: recommendations from an international consensus workshop. Reprod Sci. 2009;16:335-46.

5. Scarselli G, Rizzello F, Cammilli F, Ginocchini L, Coccia ME. Diagnosis and treatment of endometriosis. A review. Gynecol Endocrinol. 2009;25:734-40.

6. Vodolazkaia A, El-Aalamat Y, Popovic D, Mihalyi A, Bossuyt X, Kyama CM, et al. Evaluation of a panel of 28 biomarkers for the non-invasive diagnosis of endometriosis. Hum Reprod. 2012;27:2698-711.

7. Abbas S, Ihle P, Köster I, Schubert I. Prevalence and incidence of diagnosed endometriosis and risk of endometriosis in patients with endometriosisrelated symptoms: findings from a statutory health insurance-based cohort in Germany. Eur J Obstet Gynecol Reprod Biol. 2012;160:79-83. 
8. Eskenazi B, Warner M, Bonsignore L, Olive D, Samuels S, Vercellini P. Validation study of nonsurgical diagnosis of endometriosis. Fertil Steril. 2001;76:929-35.

9. Okeke TC, Ikeako LC, Ezenyeaku CC. Endometriosis. Niger J Med. 2011;20:191-9.

10. Goshtasebi A, Nematollahzadeh M, Hariri F, Montazeri A. The short form endometriosis health profile (EHP-5): translation and validation study of the Iranian version. J Ovarian Res. 2011:4:11.

11. Lemaire GS. More than just menstrual cramps: symptoms and uncertainty among women with endometriosis. J Obstet Gynecol Neonatal Nurs. 2004;33:71-9.

12. Treloar SA, Bell TA, Nagle CM, Purdie DM, Green AC. Early menstrual characteristics associated with subsequent diagnosis of endometriosis. Am J Obstet Gynecol. 2010;202:534-6.

13. Moher D, Liberati A, Tetzlaff J, Altman DG, PRISMA Group. Preferred reporting items for systematic reviews and meta-analyses: the PRISMA statement. Ann Intern Med. 2009:151:264-9.

14. Valle RF. Endometriosis: current concepts and therapy. Int J Gynaecol Obstet. 2002:78:107-19.

15. Spaczynski RZ, Duleba AJ. Diagnosis of endometriosis. Semin Reprod Med. 2003:21:193-208.

16. Kennedy S, Bergqvist A, Chapron C, D'Hooghe T, Dunselman G, Greb R, et al. ESHRE guideline for the diagnosis and treatment of endometriosis. Hum Reprod. 2005;20:2698-704.

17. Mounsey AL, Wilgus A, Slawson DC. Diagnosis and management of endometriosis. Am Fam Physician. 2006;74:594-600.

18. Denny E, Mann CH. A clinical overview of endometriosis: a misunderstood disease. Br J Nurs. 2007;16:1112-6.

19. Amer S. Endometriosis. Obstet, Gynecol Reprod Medicine. 2008;18:126-33.

20. Giudice LC. Clinical practice. Endometriosis. N Engl J Med. 2010;362:2389-98

21. Altman G, Wolcyzk M. Endometriosis: overview and recommendations for primary care nurse practitioners. J Nurse Pract. 2010;6:427-34

22. Koninckx PR, Ussia A, Adamyan L, Wattiez A, Donnez J. Deep endometriosis: definition, diagnosis, and treatment. Fertil Steril. 2012;98:564-71.

23. Acién P, Velasco I. Endometriosis: a disease that remains enigmatic. ISRN Obstet Gynecol. 2013;17:1-12.

24. Carneiro MM, Filogônio ID, Costa LM, de Ávila I, Ferreira MC. Clinical prediction of deeply infiltrating endometriosis before surgery: is it feasible? a review of the literature. Biomed Res Int. 2013;2013:1-8.

25. Schrager S, Falleroni J, Edgoose J. Evaluation and treatment of endometriosis. Am Fam Physician. 2013;2:107-13.

26. Mehedintu C, Plotogea MN, lonescu S, Antonovici M. Endometriosis still a challenge. J Med Life. 2014;7:349.

27. Bhattacharjee AK, Choudhury AP. Clinical and non-clinical presentations of endometriosis. Int J Clin Surg Adv. 2014;2:120-47.

28. Chapron C, Dubuisson JB, Pansini V, Vieira M, Fauconnier A, Barakat $H$, et al. Routine clinical examination is not sufficient for diagnosing and locating deeply infiltrating endometriosis. J Am Assoc Gynecol Laparosc. 2002;9:115-9.

29. Ballweg ML. Impact of endometriosis on women's health: comparative historical data show that the earlier the onset, the more severe the disease. Best Pract Res Clin Obstet Gynaecol. 2004;18:201-18.

30. Cheewadhanaraks S, Peeyananjarassri K, Dhanaworavibul K, Liabsuetrakul T. Positive predictive value of clinical diagnosis of endometriosis. J Med Assoc Thi. 2004;87:740-4

31. Chapron C, Barakat H, Fritel X, Dubuisson JB, Bréart G, Fauconnier A Presurgical diagnosis of posterior deep infiltrating endometriosis based on a standardized questionnaire. Hum Reprod. 2005;20:507-13.

32. Ballard KD, Mangubat MC. Can symptomatology provide clues to the diagnosis of endometriosis?: a national case-control study of 5,544 women with endometriosis. J Minim Invasive Gynecol. 2007;14:S10-S154.

33. Flores I, Abreu S, Abac S, Fourquet J, Laboy J, Ríos-Bedoya C. Self-reported prevalence of endometriosis and its symptoms among Puerto Rican women. Int J Gynaecol Obstet. 2008;100:257-61.

34. Greene R, Stratton P, Cleary SD, Ballweg ML, Sinaii N. Diagnostic experience among 4,334 women reporting surgically diagnosed endometriosis. Fertil Steril. 2009:91:32-9.

35. Ballard K, Lane H, Hudelist G, Banerjee S, Wright J. Can specific pain symptoms help in the diagnosis of endometriosis? a cohort study of women with chronic pelvic pain. Fertil Steril. 2010;94:20-7.
36. Nnoaham KE, Hummelshoj L, Kennedy SH, Jenkinson C, Zondervan KT Developing symptom-based predictive models of endometriosis as a clinical screening tool: results from a multicenter study. Fertil Steril. 2012;98:692-r.

37. Hadisaputra W. Clinical signs, symptoms and serum level of interleukin-6 and tumor necrosis factor in women with or without endometriosis. APJR. 2013;2:142-5.

38. Kashima K, Ishimaru T, Okamura H, Suginami H, Ikuma K, Murakami T, et al. Familial risk among Japanese patients with endometriosis. Int J Gynaecol Obstet. 2004;84:61-4

39. Hediger ML, Hartnett HJ, Louis GM. Association of endometriosis with body size and figure. Fertil Steril. 2005;84:1366-74.

40. Parazzini F, Cipriani S, Bianchi S, Gotsch F, Zanconato G, Fedele L. Risk factors for deep endometriosis: a comparison with pelvic and ovarian endometriosis. Fertil Steril. 2008;90:174-9.

41. Sinaii N, Plumb K, Cotton L, Lambert A, Kennedy S, Zondervan K, et al. Differences in characteristics among 1,000 women with endometriosis based on extent of disease. Fertil Steril. 2008:89:538-45.

42. Bazot M, Lafont C, Rouzier R, Roseau G, Thomassin-Naggara I, Daraï E. Diagnostic accuracy of physical examination, transvaginal sonography, rectal endoscopic sonography, and magnetic resonance imaging to diagnose deep infiltrating endometriosis. Fertil Steril. 2009;92:1825-33.

43. Lafay Pillet MC, Schneider A, Borghese B, Santulli P, Souza C, Streuli I, et al. Deep infiltrating endometriosis is associated with markedly lower body mass index: a 476 case-control study. Hum Reprod. 2012;27:265-72.

44. Chapron C, Lafay- Pillet MC, Monceau E, Borghese B, Ngo C, Souza C, et al. Questioning patients about their adolescent history can identify markers associated with deep infiltrating endometriosis. Fertil Steril. 2011;95:877-81.

45. Peterson CM, Johnstone EB, Hammoud AO, Stanford JB, Varner MW, Kennedy $A$, et al. Risk factors associated with endometriosis: importance of study population for characterizing disease in the ENDO Study. Am J Obstet Gynecol. 2013;208:451e1-451e11.

46. Borghese B, Chartier M, Souza C, Santulli P, Lafay-Pillet MC, de Ziegler D, et al. $\mathrm{ABO}$ and Rhesus blood groups and risk of endometriosis in a French Caucasian population of 633 patients living in the same geographic area. Biomed Res Int. 2014;2014:618964

47. Cavaggioni G, Lia C, Resta S, Antonielli T, Benedetti Panici P, Megiorni F, et al. Are mood and anxiety disorders and alexithymia associated with endometriosis? A preliminary study. Biomed Res Int. 2014:2014:786830.

48. Xie J, Kvaskoff M, Li Y, Zhang M, Qureshi AA, Missmer S A, et al. Severe teenage acne and risk of endometriosis. Hum Reprod. 2014;29:2592-9.

49. Vercellini $P$, Buggio L, Somigliana E, Dridi D, Marchese M A, Viganò P. 'Behind blue eyes': the association between eye colour and deep infiltrating endometriosis. Hum Reprod. 2014:29:2171-2175.

50. Tu Frank F, Hongyan DU, Goldstein GP, Beaumont JL, Zhou Y, Brown WJ. The influence of prior oral contraceptive use on risk of endometriosis is conditional on parity. Fertil Steril. 2014;101:1697-704.

51. Heitmann RJ, Langan KL, Huang RR, Chow GE, Burney RO. Premenstrual spotting of two or more days is strongly associated with histologically confirmed endometriosis in women with infertility. Am J Obstet Gynecol. 2014;211;4:358.e1-6.

52. Walch K, Kernstock T, Poschalko-Hammerle G, Gleiß A, Staudigl C, Wenzl R. Prevalence and severity of cyclic leg pain in women with endometriosis and in controls - effect of laparoscopic surgery. Eur J Obstet Gynecol Reprod Biol. 2014;179:51-7.

53. Barbosa JS, Yamamoto MMW, de Medeiros MAS, Kubiszeski EH, Banhara CR, de Medeiros SF. Clinical and endocrine features of Brazilian infertile women with or without endometriosis: A comparative cross-sectional study. APJR. 2014:3:275-81.

54. Nnoaham KE, Webster P, Kumbang J, Kennedy SH, Zondervan K. Is early age at menarche a risk factor for endometriosis? A systematic review and meta-analysis of case-control studies. Fertil Steril. 2012;98:702-12.

55. Parazzini F, Cipriani S, Bravi F, Bravi F, Pelucchi C, Chiaffarino F, et al. A metaanalysis on alcohol consumption and risk of endometriosis. Am J Obstet Gynecol. 2013:209:106.e1-10.

56. Bungum HF, Vestergaard C, Knudsen UB. Endometriosis and type 1 allergies/immediate type hypersensitivity: a systematic review. Eur J Obstet Gynecol Reprod Biol. 2014;179:209-15.

57. Bonocher CM, Montenegro ML, Silva JC, Ferriani RA, Meola J. Endometriosis and physical exercises: a systematic review. Reprod Biol Edocrinol. 2014;12:4

58. Kennedy S. Who gets endometriosis? Women's Health Med. 2005;2:18-9. 
59. Matalliotakis I, Cakmak H, Goumenou A, Sifakis S, Ziogos E, Arici A. ABO and Rh blood groups distribution in patients with endometriosis. Arch Gynecol Obstet. 2009;280:917-9.

60. Demir B, Dilbaz B, Zahran M. ABO and Rh blood groups distribution in patients with endometriosis. Arch Gynecol Obstet. 2010;281:373-4.

61. Howard FM. Clinical predictors of a surgical diagnosis of endometriosis. J Minim Invasive Gynecol. 2005;12:6-7.

Submit your next manuscript to BioMed Central and take full advantage of:

- Convenient online submission

- Thorough peer review

- No space constraints or color figure charges

- Immediate publication on acceptance

- Inclusion in PubMed, CAS, Scopus and Google Scholar

- Research which is freely available for redistribution 